\title{
Interpreting Textbooks for BTI Students in China: Retrospection, Problems and Prospect
}

\author{
Yue Wang ${ }^{1}$ \\ ${ }^{1}$ Department of Foreign Studies, North China Electric Power University, Baoding, China \\ Correspondence: Yue Wang, Department of Foreign Studies, North China Electric Power University, No. 619 \\ Yonghuabei Street, Baoding, China.
}

Received: August 3, 2021

Accepted: August 27, 2021

Online Published: August 30, 2021

doi: $10.5539 /$ elt.v14n9p61

URL: https://doi.org/10.5539/elt.v14n9p61

\begin{abstract}
As the language service sector continues to develop, the education for undergraduate translation majors (or BTI: BA Translation and Interpreting) calls for more solid support from well-compiled textbooks. The study investigates the general publication status of interpreting textbooks for BTI students and takes a close look at four representative examples. The findings reveal that traditional interpreting textbooks have such problems as disrespect for the rules of teaching, incomplete portrait of the interpreting profession and the failure to keep pace with the time, therefore can no longer satisfy the need that an evolving language service sector places on BTI students. Considering the teaching objectives of BTI and the new definition of "translation competence" in the "Teaching Guide for Undergraduate Translation Major" issued in 2020, the author proposes that interpreting textbooks need to enrich the teaching contents, have more interpreting practitioners as editors and integrate various modern technologies to be as multi-dimensional as possible.
\end{abstract}

Keywords: BTI, IT-assisted interpreter training, textbook compilation

\section{Introduction}

The rapid advancement of the language service sector has placed a higher demand on language majors. In particular, undergraduate translation majors often find themselves face with greater challenges as they enter into the job market. The responsibility naturally falls upon the shoulders of educators and researchers to prepare students with solid translation skills, bi-lingual competence and the ability to use tools, especially in interpreting classes which are embracing radical changes as transformative technology and AI continue to shape the interpreting profession.

Undoubtedly, teaching materials, passing on both teaching content and philosophy, deserve a significant place in the pedagogical process. Teaching materials can take many different forms. Self-collected materials suitable for interpreter training have been adopted in classrooms, but many teachers still favor traditionally compiled textbooks for reasons of convenience. It has been rightly stated that "textbooks are playing an increasingly important role, affecting not only translation and interpreting studies as a discipline, but also the social and economic progress of the nation and the national status in the global community." (Tao, 2017) Yet a close examination of the relevant papers on CNKI (Note 1) points to the insufficiency of interest and reflection in this area. Therefore, through adoping the method of document analysis and comparison, this paper combs the past development of interpreting textbooks for undergraduate translation majors, attempts to identify the existing problems and put forward suggestions for future textbook compilation, so as to enhance the quality of interpreter training as a part of BTI education and better prepare students for the profession.

\section{BTI, the Curriculum and Teaching Objectives}

In 2006, the Ministry of Education approved the piloting of "Undergraduate Translation Majors" in three universities, marking the beginning of a brand-new major. Statistics show that the number of universities which have included this major in their undergraduate programs has experienced continued growth. By the end of 2018, it has been set up in 272 universities, covering 9 language pairs (Zhong, 2019).

In 2020, the "Teaching Guide for Undergraduate Translation Major" (hereinafter referred to as the Teaching Guide) was newly released. Three interpreting-related courses are listed in the suggested curriculum as core courses: Liaison Interpreting, Consecutive Interpreting and Topic-Based Interpreting; and two are listed as 
optional courses: Sight Translation (generally regarded as a course to prepare students for their simultaneous interpreting skills) and Simultaneous Interpreting. These five courses are to be taken by students from the $4^{\text {th }}$ to the $6^{\text {th }}$ term, and account for a significant amount of 10 credits. In addition, in the Teaching Guide, "translation competence" has been given definition for the first time (Note 2) - defined as "the ability to conduct language transfers with a certain amount of translation knowledge, methods and techniques, covering bilingual competence, supra-linguistic competence, tool-using competence and strategic competence, etc."-and the cultivation of translation competence is regarded as a central task in teaching undergraduate translation majors.

Another related document- "National Standards of Teaching Quality for Undergraduate Foreign Language and Literature Majors" (hereinafter referred to as the National Standards) - was initiated in 2013 by the Ministry of Education and has provided basic guidance for BTI education. In reflection upon his compilation efforts, Zhong (2015) stressed the relationship between the teaching methodology and teaching methods, as well as the relationship between traditional textbooks and extra teaching resources. He pointed out that we should include various teaching methods such as task-based approach, project-based learning (PBL) and case methods of teaching, to name but a few; advocated the full application of IT, multi-media tools and computer-aided translation (CAT) platforms for education purposes; and called on the construction of teaching resource pools to back up traditional textbooks.

From the documents, it's clear that the objectives for the cultivation of undergraduate translation majors are to equip students with all-around translation capacity for the fast-evolving language service sector; and it's also obvious that textbooks have a significant role to play in the cultivation process and deserve much more of our research efforts.

\section{The Current Situation of Interpreting Textbooks for BTI}

Currently, there are a great number of interpreting textbooks in the market. Researchers have investigated the publication status crossing different time spans and found that the number is still growing (Tao, 2017; Zhao, 2017). These textbooks can be categorized into different types, such as textbooks for examination purposes, textbooks structured in theme orders, textbooks for special interpreting such as business interpreting or legal interpreting, and textbooks structured to introduce different interpreting skills.

As it is impossible to survey all of them, the author has picked four representative textbooks, had a close examination and listed their basic information in the following table. The criteria for the selection are: the books are published in the $21^{\text {st }}$ century by authoritative publishing houses; skills mentioned in the books should be by far the most important ones to be acquired by undergraduate students; and the books should cover topics that students will most likely encounter in the job market.

Table 1. Survey list of interpreting textbooks (English/Chinese only) (Note 3)

\begin{tabular}{|c|c|c|c|c|}
\hline No. & Title & Author & Press & Publishing Time \\
\hline 1 & Interpreting for General Purposes & Mei Deming & Peking University Press & 2007.4 \\
\hline 2 & $\begin{array}{l}\text { An Advanced Course of } \\
\text { Interpretation }\end{array}$ & Mei Deming & $\begin{array}{l}\text { Shanghai Foreign Language } \\
\text { Education Press }\end{array}$ & 2011.10 \\
\hline 3 & Basics of Interpreting Skills & $\begin{array}{l}\text { Deng Yi \& } \\
\text { Liu Ying }\end{array}$ & $\begin{array}{l}\text { Shanghai Foreign Language } \\
\text { Education Press }\end{array}$ & 2016.10 \\
\hline 4 & $\begin{array}{l}\text { Note-taking of English-Chinese } \\
\text { Interpretation-A Field Guidance }\end{array}$ & $\begin{array}{l}\text { Wu } \\
\text { Zhongming }\end{array}$ & Wuhan University Press & 2017.1 \\
\hline
\end{tabular}

The structures of these four textbooks vary. Both the "Interpreting for General Purposes" and "An Advanced Course of Interpretation" are organized by units featuring various themes, but are different in how interpreting skills are introduced: There are 16 units in the "Interpreting for General Purposes", each contains the following components: "Vocabulary work", "Text interpreting", "Notes on the text", "Developing vocabulary and expression", "Interpreting practice", "Interpreting tips and skills", "Exercise for skills", "Reference translation", and "Tape script for listening interpreting"; while interpreting-related skills are introduced in a separate part following 15 units of different themes in "An Advanced Course of Interpretation". Both books offer model tests towards the end, and the "Interpreting for General Purposes" also includes appendixes with names of countries, regions, international organizations and companies. "Basics of Interpreting Skills" is organized by units featuring different interpreting skills. Interpreting materials which could contribute to consolidating the particular skill are selected in the relevant unit. "Note-taking of English-Chinese Interpretation-A Field Guidance" is designed to develop the basic note-taking skill for consecutive interpreting, and therefore follows the sequence of the 
materials' lengths: interpreting practices of sentences, paragraphs and passages, with hand-written note demonstrations in each section.

\section{Problems of Existing Textbooks}

\subsection{Neglect of the Rules of Teaching}

Instructional System Design (ISD) has been put forward in the 1960s to address multiple problems in skills training. It advocates the gradual and continued development of complex skills, believing that "instruction is most likely to be effective if severe constraints are placed on the amount of new structures that must be added to already known atoms to yield each new knowledge unit" (Derry \& Lesgold, 1996:787). Interpreting is generally regarded as a complex skill, as it requires interpreters to have linguistic capacity, translation competence and sufficient world knowledge. At the same time, the listening analysis effort, the production effort and the short-term memory effort are all required to accomplish the complex task (Gile, 2009). Following the scientific instructions of ISD, interpreting competence could be best cultivated by adding complex component skills to simple (prerequisite) skills. Lack of the instructional sequencing could lead to ineffective learning, as trainees are constantly forced to juggle with multiple component skills simultaneously and struggle to consolidate any one of them.

Yet an investigation of the textbooks suggests that the right sequence has oftentimes been overlooked. Firstly, Chinese to English interpreting materials are arranged in front of English to Chinese materials. Undergraduate students are still in the process of building their language skills. Given that they still lack interpreting experience, a rush to render into the second language could appear to be a daunting task and do nothing to boost their confidence. Secondly, some textbooks offer equal lengths of source materials for interpreting from the beginning module to the end. For instance (Note 4), "Passage one" (a Chinese speech as source text) in the second unit of "An Advanced Course of Interpretation" contains roughly the same amount of words as "Passage one" (a Chinese speech as source text) in the fourteenth unit. Besides, they are both texts with extensive descriptive language embedded with four-character words, which could pose significant cognitive challenges to novice interpreters (Seleskovitch \& Lederer, 2011:66). Thirdly, the familiarity of background knowledge plays an important role in the comprehension of the source texts, but some textbooks have failed to precede unfamiliar topics with familiar ones. It is suggested that a survey among students to gain a clear understanding of their degree of familiarity with different topics is highly necessary before compiling textbooks.

\subsection{Incomplete Portrait of the Interpreting Profession}

Interpreting has some defining features which set it apart from translation and deserve special attention in the compilation of teaching materials. However, the majority of pedagogical materials fail to depict the interpreting practice in its true colors.

Firstly, the one-timeliness of the interpreting activity is badly reflected in textbooks. The definition of interpreting has been presented by many researchers in various forms. The most famous one has been given by Franz Pöchhacker (2016:11) in the following words: "Interpreting is a form of Translation in which a first and final rendition in another language is produced on the basis of a one-time presentation of an utterance in a source language." In simple words, the researcher underlines that interpreting is a one-time activity in terms of both the listening of source texts and the rendering of target texts. Naturally, in real interpreting scenarios, interpreted texts could vary and should be presented in short and concise manner, yet both source texts and the reference version of the interpreted texts are always given in long and extended written forms. This could lead students to pursue the perfect "translated" text when practicing interpreting, which will greatly affect their flow of the delivery. For instance (Note 5), in unit seven of "An Advanced Course of Interpretation", the reference text of an introductory speech of Fudan University reads: "The beginning of the $20^{\text {th }}$ century witnessed an impoverished and enfeebled China that slumbered in dim prospects." The sentence is long, complete and beautifully translated, yet interpreters would to a large extent struggle to cope with such long sentences embedded with metaphorical expressions. On the contrary, interpreters are more likely to produce sentences such as "In the beginning of the $20^{\text {th }}$ century, China was poor, weak in national power, and struggled to find a way to move forward." It is therefore suggested that textbooks provide clear and short sentences that follow the linear sequence of the source text and the pattern of consecutive interpreters' notes, which is especially important for novice interpreters.

In addition, as a one-time activity, interpreting requires interpreters to be as well-prepared as possible. In this sense, pre-interpreting preparation is an inseparable part of the activity, yet very few words can be found on textbooks as to how to do the preparation. Words and expressions relevant to the given topic are usually listed before the text, but what an interpreter needs in field interpreting is not just specific terms, but also the 
knowledge behind them. Search engines and methods are gateways leading to the knowledge required but are seldom covered.

Secondly, paralinguistic elements could in a large extent determine whether the original oral message is well received by the interpreter, but the significance of this is rarely mentioned. In real interpreting scenarios, interpreters often encounter speakers with various accents - understanding many of them has been proven to be extremely challenging even for expert interpreters, but the textbooks seem to have built a safe haven for students by collecting audio texts only with standard pronunciation. In the post-COVID era, remote interpreting has been adopted by many conference organizers to save costs and keep a safe distance. Insufficient visibility of facial expressions of both the speaker and the audiences on computer screens-important paralinguistic clues for interpreters to get the message across - has posed great challenges to the interpreting profession (Moser-Mercer, 2005). However, none of the textbooks in this study has touched upon instructions on building student interpreters' capacity in dealing with such difficulties in remote interpreting.

Thirdly, the interacting role of interpreters has long been debated in the research community yet rarely reflected in the textbooks of interpreting for undergraduates. From the description of "conduit", "channel" and "switching device", these metaphors which depict interpreters as mechanical language transferring machines have been gradually replaced by expressions of "cultural broker", "communication facilitator" and "intercultural mediator". The transformation shows that interpreters do have an active part to play in gatekeeping the information and facilitating communication (Pöchhacker, 2016). Yet it's evident that many textbooks-including the four that the author surveyed - still focus primarily on the faithful convey of the message - which is too ideal to be true. How to make culturally informed language decisions when serving as community interpreters, how to monitor the turn-taking in bilateral interpreting and how to avoid depriving the interest of the underprivileged while sticking to professional ethics of neutrality are real issues that interpreters need to consider, but only rare traces of such discussions can be found in textbooks.

\subsection{Failure to Keep Pace with the Time}

Interpreting services are usually offered in international conferences where topics heatedly discussed and debated are relevant to today's world. Unlike translation textbooks, interpreter training materials should reflect what is going on in the current society. However, due to the long period a textbook has to go through before being published, many textbooks contain materials that are outdated and less relevant. For instance (Note 6), "Note-taking of English-Chinese interpretation-A Field Guidance" still offers students speech scripts and news reports of the 2008 Beijing Olympics, despite the fact that the Olympic Games held in Beijing has been held 10 years prior and is no longer the focus of international conferences and bilateral meetings.

Additionally, the rapid development of interpreting technologies has transformed the industry in many ways. Researchers have investigated the essential characteristics of these technologies and put them into different categories, such as terminology banks for interpreters to share their preparation efforts, technology-mediated platforms including Zoom or Tencent Meeting to organize online conferences, and machine interpreting technologies such as "Iflytech" which could provide real-time voice recognition and language transfer (Wang \& Yang, 2019). Though IT-assisted interpreting has already become the trend for the future, IT-assisted interpreter training has not been achieved through textbooks. As of 2020, there is still no textbook offering instructions for students to prepare them for the interpreting job of today and tomorrow.

\section{Suggestions on Future Textbook Compilation}

As the Teaching Guide proposes, undergraduate translation majors are supposed to build their bilingual competence, supra-linguistic competence, tool-using competence and strategic competence. To better cultivate these translation and interpreting-related capacities, textbooks should undergo major shifts to reflect the pedagogical rules, the true interpreting practice and the rapidly changing profession.

To start with, educators and researchers should take the lead to embrace modern technologies as they compile modern textbooks. We could learn from the successful experience of Europe, a pioneer in the integration of traditional textbooks and digital teaching resources. "EU Speech Repository" and "Speechpool" which contain renewed interpreting materials covering various topics have been widely adopted in many translator and interpreter training programs. Apart from materials for educational purposes, other types of digital resources have also been developed, compiled and stored in different corpuses for evaluation, assessment and meta-learning, etc. (Deng \& Xu, 2020) There are many advantages to the integrated pedagogical system. For example, the videos could reflect real conference scenarios with paralinguistic elements such as facial expression of the speaker better shown on the screen; without the long publication process, interpreting materials could capture contemporary topics in a timely manner. Several Chinese researchers have also pointed to the building of 
pedagogical corpuses and the use of e-book compiling tools such as "ibook", in order to bring the advantages of modern technology into full play and better suit the special demand of interpreter training (Tao, 2010; Deng \& $\mathrm{Xu}, 2020 ; \mathrm{Xu}, 2015)$.

Secondly, interpreting practitioners should represent a larger portion of the authors and editors of interpreting textbooks. A tricky issue in the interpreting profession is that not many interpreting practitioners are involved in interpreter training, while the teaching staff in universities have very little field interpreting experience. It's therefore not difficult to understand that the existing textbooks do not help with describing what interpreting really is. Both educational authorities and universities should issue policies and allocate special funds to encourage more freelance interpreters to join the compilation efforts, so as to bring more true interpreting experiences into classrooms and improve the teaching quality.

Last but not least, the content of textbooks should be enriched. Currently, most textbooks are compiled only by gathering interpreting materials, but there is a lack of interpreting theories behind the introduction of interpreting skills. Students can therefore learn how to do interpreting, but they cannot comprehend why interpreting is practiced this way. Besides, textbooks compiled based on pedagogical theories will improve both the teaching and learning efficiency. In addition, as the Teaching Guide proposes, translation competence is a comprehensive concept covering supra-linguistic and strategic competence. Therefore, textbooks should include more cross-cultural knowledge, in-depth discussion on renewed topics, introductions on ethics, teamwork and values, as well as instructions on how to boost pressure tolerance capability, etc.

\section{Conclusion}

A close look at interpreting textbooks for undergraduate translation majors (BTI) unveils many existing problems. Traditional textbooks cannot get away with multiple issues: rules of teaching are not strictly obeyed, the interpreting profession is not fully portrayed, and the books are not assisted by modern technology to include more contents that reflect the trends of the time. Only through continued efforts to invite more interpreting practitioners to join the team of textbook editors, enrich the teaching content and make full use of information technology, can interpreting textbooks enter a new era and offer solid support for the education of BTI students.

\section{Acknowledgments}

This research is supported by the "Fundamental Research Funds for the Central Universities" (Grant number: 2019MS142).

\section{References}

Deng Juntao, \& Xu Mianjun. (2020). Developing Digital Resources for Interpreting Teaching: Implications of European Experience. Shanghai Journal of Translators, (3), 62-66.

Derry, S., \& Lesgold, A. (1996). Toward a Situated Social Practice Model for Instructional Design. In D. C. Berliner \& R. C. Calfee (Eds.), Handbook of educational psychology (pp. 787-806). New York: Simon and Schuster Macmillan.

Gile, D. (2009). Basic concepts and models for interpreter and translator training. Amsterdam/Philadelphia: John Benjamins Publishing Company. https://doi.org/10.1075/btl.8

Moser-Mercer, B. (2005). Remote Interpreting: Issues of Multi-sensory Integration in a Multiingual Task. Meta, 50(2), 727-738. https://doi.org/10.7202/011014ar

Pöchhacker, F. (2016). Introducing interpreting studies (2nd ed.). London \& New York: Routledge. https://doi.org/10.4324/9781315649573

Seleskovitch. D., \& Lederer. M. (1990/2011). Pétagogie raisonnée de l'interprétation. (Yan Suwei \& Shao Wei, Trans.). Beijing: China Translation and Publishing Corporation.

Tao Youlan. (2010). Corpus Supported Interpreting Textbooks for Translation Majors. Foreign Language World, (4), 2-8.

Tao Youlan. (2017). Translation Textbook Compiling in the Perspective of the Extended Translatology. Shanghai Journal of Translators, (6), 83-88.

Wang Huashu, \& Yang Chengshu. (2019). Interpreting Technologies in the Era of Artificial Intelligence: Concepts, Influences and Trends. Chinese Translators Journal, (6), 69-79.

$\mathrm{Xu}$ Wensheng. (2015). Research and Application of Interpreting Textbooks Compiled with Ibooks in the Era of Big Data. Chinese Translators Journal, (3), 63-66. 
Zhao Changhan. (2017). Development Principles and Countermeasures of Profession-Oriented Interpreting Textbooks. Technology Enhanced Foreign Language Education, (176), 60-65.

Zhong Weihe. (2015). Interpretation of the "National Standards of Teaching Quality for Undergraduate Translation Majors". Foreign Language Teaching and Research, 47(2), 289-296.

Zhong Weihe. (2019). Education for Translation Majors in the Forty Years After Reform and Opening Up: Achievements, Challenges and Developments. Chinese Translators Journal, (1), 68-75.

\section{Notes}

Note 1. China National Knowledge Infrastructure, the most widely acknowledged academic database in China offering published research in various areas

Note 2. The definition can be found on page 37 of the Teaching Guide.

Note 3. Due to the limit of the author's language ability, only textbooks of English-Chinese interpreting are selected. Textbooks covering other language pairs are not surveyed in this research.

Note 4 . The example can be found on page 44 and page 369 of the textbook.

Note 5. The example can be found on page 195 of the textbook.

Note 6 . The example can be found on page 26 of the textbook.

\section{Copyrights}

Copyright for this article is retained by the author(s), with first publication rights granted to the journal.

This is an open-access article distributed under the terms and conditions of the Creative Commons Attribution license (http://creativecommons.org/licenses/by/4.0/). 